\title{
Increasing Self-Compassion in Young People through Virtual Reality
}

\author{
Nilufar Baghaei ${ }^{1}$, Sylvia Hach², Imran Khaliq ${ }^{3}$, Lehan Stemmet ${ }^{4}$, Jamuna Krishnan ${ }^{5}$, John Naslund ${ }^{6}$, \\ Hai-Ning Liang ${ }^{7}$, Hamid Sharifzadeh ${ }^{8}$ \\ ${ }^{1}$ Department of Information Technology, Otago Polytechnic Auckland Campus (OPAIC), Auckland 1010, New Zealand \\ ${ }^{2,8}\{$ Clinical Research, School of Community Studies; School of Computing \& IT\}, Unitec Institute of Technology, Auckland 1142, New Zealand \\ ${ }^{3}$ Media Design School, 92 Albert St, Auckland CBD, Auckland 1010, New Zealand \\ ${ }^{4}$ Department of Management, Otago Polytechnic Auckland Campus (OPAIC), Auckland 1010, New Zealand \\ ${ }^{5}$ Mental Health Services, Mid-Central District Health Board (MidCentral DHB), New Zealand \\ ${ }^{6}$ Global Health and Social Medicine, Harvard Medical School, Boston, MA 02115, United States \\ ${ }^{7}$ Department of Computer Science and Software Engineering, Xi'an Jiaotong-Liverpool University, China \\ \{nilufar.baghaei; lehan.stemmet\}@op.ac.nz; shach@unitec.ac.nz; john_naslund@hms.harvard.edu
}

\begin{abstract}
Mental health conditions pose a major challenge to healthcare providers and society at large. According to the Mental Health Foundation of New Zealand, one in five people will develop a serious mood disorder, including depression, at some time in their life [2]. Early intervention can have significant positive impact on a person's prognosis, particularly important in affecting outcomes for young people [38]. Co-designed solutions to improve resilience and well-being in young people have specifically been recognised as part of the National Suicide Prevention Strategy and the New Zealand Health Strategy. Innovative interventions that support long-term change for individuals are urgently needed [10].

Self-compassion/self-criticism constitutes a protective/risk factor with regard to developing and maintaining depression [3]; particularly in young people [4]. Self-criticism is one of the major psychological factors, defined as dominant response style of negative evaluation and judgement of self to perceived failure [5]. One effective method to increase self-compassion and reduction in depression may be to address self-criticism through compassion-focused therapy [6].

Virtual Reality (VR) in Health is an emerging field. It is becoming more commonplace with the advent of affordable consumer head mounted devices, and has significant potential for the understanding, assessment and treatment of mental health problems [7]. It can provide a non-threatening, zero risk environment which allows for free exploring of different strategies [16]. We propose to take this new technology and codesign Virtual Reality scenarios with young people, which focuses on real world situations that impact the sample group most and assists them to view these experiences with a selfcompassionate lens. This is achieved by being taught compassionate manners of responding to a scenario and by switching perspective. We provide an overview of an initial proofof-concept study, propose a study in different social settings and highlight key points for discussion pertaining to technology use, data safety, privacy, and considerations for addressing depressive symptoms necessary to advance this work.
\end{abstract}

Keywords: virtual reality, mental health, self-compassion.

\section{INTRODUCTION}

Mental health conditions are a major challenge for society, healthcare providers, and health systems. The World Health Organization predicts that by 2030 mental health conditions will be the leading disease burden globally [1]. Mental health services are struggling to meet the needs of users and fail to reach large proportions of those in need across most countries.

According to the Mental Health Foundation of New Zealand, one in five people will develop a serious mood disorder, including depression, at some time in their life [2]. Early intervention can have significant positive impact on a person's prognosis, particularly important in affecting outcomes for young people [38]. Co-designed solutions to improve resilience and well-being in young people have specifically been recognised as part of the National Suicide Prevention Strategy and the New Zealand Health Strategy. Innovative interventions that support long-term change for individuals are urgently needed [10].

Self-compassion/self-criticism constitutes a protective/risk factor with regard to developing and maintaining depression [3]; particularly in young people [4]. Self-criticism is one of the major psychological factors, defined as dominant response style of negative evaluation and judgement of self to perceived failure [5]. One effective method to address self-criticism may be to increase self-compassion through compassion-focused therapy [6].

To implement compassion-focused therapy, the general approach is in-vivo exposure based [9]. The patient is exposed to a situation that causes distress so that the therapist may help the patient to highlight the importance of developing a capacity to mindfully access, tolerate, and direct affiliative motives and emotions, for themselves and others, and cultivate inner compassion to organize mentally healthy behaviors. To create such situations in the real world is resource demanding, and innovative interventions that support long-term change for individuals are urgently needed [7]. To make this treatment feasible and timely to everyone who needs it, Virtual Reality (VR) technology may be useful.

Virtual technologies have the potential for supporting personal and clinical change. Real environments can be replaced with virtual ones, thereby allowing a transformation of our external experience. When a life-sized virtual body substitutes a person's real body in immersive virtual reality, it typically generates an illusion of body ownership over the virtual body. The illusion of body ownership is the perceptual illusion that the body is one's own and relies on a first-person perspective view of the body [12, 13] and synchrony between touches seen on the virtual body and felt on the real body [14] or synchrony between real and virtual body movements through real-time motion capture. Recent evidence shows that embodiment has a variety of physiological and psychological consequences that indicate that the person has identified with or taken on attributes of the virtual body, including changes in size perception after embodiment in a child body, and changes in implicit racial attitudes after embodiment in a body with a different skin colour $[8,15]$. A high level of personal efficacy and self-reflectiveness is typically generated in the virtual environment by an increased sense of presence and emotional engagement. Moreover, VR can modify our inner experience by structuring, altering, and/or replacing our bodily selfconsciousness $[10,11]$.

Systematic reviews available for VR support the use of this technology in the treatment of anxiety disorders, phobia, stress- 
related disorders, obesity and eating disorders, and pain management, where gains are generalised to real life $[16,17,9$, 18]. However, there is little evidence in the literature for or against using VR for promoting self-compassion and/or the treatment of depression and it is very much an emerging field [7, $19,20,10]$.

\section{Research Question}

Our aim is to design and implement a VR environment to improve self-compassion, which reduces self-criticism and in the long run can influence recovery from depression. Building on earlier research conducted by Falconer et al [7], our research question is whether the effects of calming virtual characters down in different social settings could be exploited to increase self-compassion in young people with depression or history of mood changes. A video of the Falconer [7] experiment can be viewed here: https://www.youtube.com/watch?v=GwxJVCESc-E

We propose to replicate the same experiment with a younger population (aged 18-25), but also build on the work that has been done so far. We will utilise different social settings:

- $\quad$ an upset child (Falconer replication)

- receiving a bad grade

- upset about having to give talk

- job interview

- falling out of love

- bullying

An earlier study has shown a significant improvement in participants' self-compassion as a result of exposure to VR compassion focused/mental health therapy [7]. As part of our proposal, we aim to:

- provide increased practice/exposure and target a younger audience

- increase the chance of generalisation to everyday life.

- employ better VR visualisation, e.g. assigning more realistic hand gestures and facial expressions to the characters in the virtual world.

- target young adults (18-25), as in most countries mental healthcare services for children and young people do not provide satisfactory care, and the gap between need and access is broadest for those aged 12-25 years [44].

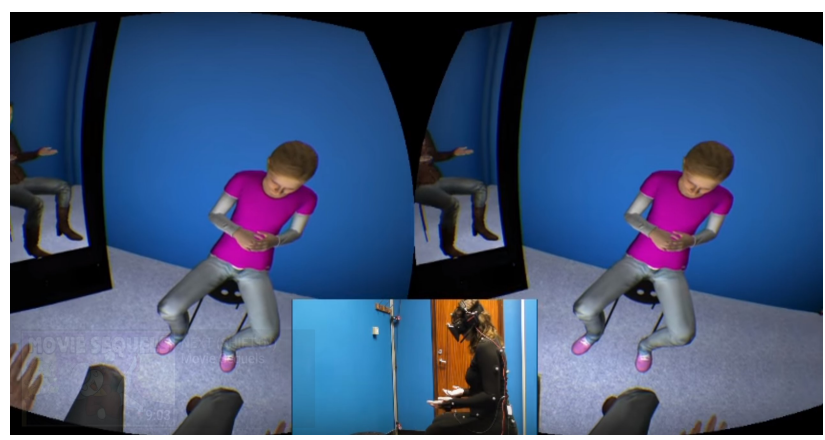

Figure 1: Falconer experiment - the participant delivers compassion to a virtual child [7].

\section{Methodology}

To answer our research question, we aim to recruit roughly 40 participants divided into one control and one experimental group. 20 people will be randomly allocated to each group. The participants will be aged 18-25 years and they may or may not have a history of depression and/or mood changes (determined through self-report at the beginning of the experiment). This study is a proof of concept and once we have a prototype and some pilot results, we will recruit a larger sample to enable efficacy testing.

The primary outcome measure will be the Patient Health Questionnaire-9 (PHQ-9) [39], a measure often used to assess outcomes in psychological treatments for depression. This measure assesses symptoms over the previous two weeks and comprises nine items scored 0 ('not at all'), 1 ('several days'), 2 ('more than half the days') or 3 ('nearly every day'). A score of 10 or greater on the PHQ-9 suggests mild to moderate depressive symptoms [45]. A reduction of at least five points will indicate reliable change [7].

The Self-Compassion and Self-Criticism Scale (SCCS) [40] consists of five scenarios that are potentially self-threatening and can elicit varying degrees of self-criticism or self-compassion (e.g. 'You arrive home to find that you have left your keys at work'). Participants are asked to imagine that these scenarios are happening to them now and rate on 7-point scales from 1 ('not at all') to 7 ('highly') the extent to which they would react to themselves in a harsh, contemptuous, critical, soothing, reassuring, and compassionate manner [7]. The positive ratings are summed to generate the Self Compassion Scale (range 15105 ) and the negative ratings generate the Self-Criticism Scale (range 15-105).

To determine if there are changes in response to the VR environment relative to the control, we will collect pre-test and post-test measures of depression using the PHQ-9 and selfcompassion using the SCCS form. We will have six VR sessions with three-day intervals (twice a week for three weeks), followed by a post- test (SCCS and PHQ-9 forms) after each session, and a post-test questionnaire at the end of three weeks, asking the participants to describe their experience. This be supplemented with a focus group discussion with potential VR users and mental health professionals to further elicit participant feedback regarding VR feasibility/acceptability and to inform further refinements to the proposed environment. Participants will be presented with all six scenarios every time and will be asked to choose the order the scenarios are presented to keep them more engaged.

Our hypothesis is that interventions using immersive VR may have significant impact on increasing participants' selfcompassion and decreasing self-criticism and will pave the way for clinical use of this technology in the future. This proof-ofconcept study serves as an important step for determining the feasibility and acceptability of using VR interventions for addressing depressive symptoms.

\section{Discussion}

As part of the International Symposium on Mixed and Augmented Reality (ISMAR 2019) workshop on AR/Mixed Augmented Reality and Mental Health, we will use the following points for further discussion:

- Given that social aptitude, interaction and connection is a defining and consistent aspect of all psychological health indicators within the Diagnostic and Statistical Manual of Mental Disorders (DSM), how do we mitigate and control for the need to form human-human bonds within a VR based therapy?

- Is there a likelihood that VR technology itself could generate a new dependency? 
- How do we control for individuals who may become very reliant on the VR technology as an avoidance coping strategy?

- How do we ensure that individuals who engage with VR as a therapeutic tool know how to and when to seek professional help when for example their condition does not improve or becomes worse (similar to individuals who self-medicate when they should be seeing a health professional)?

- How do we ensure, with the increasing use of these sorts of technologies, that individuals who download and use it understand the difference between research informed tools and less robust tools - in other words, could they go for the cheapest option rather than the best option based on the generalization that all VR and similar tools are useful?

- Should VR tools be used as part of a mental health intervention, with a health care professional/therapist being present in the room or with supplemented with remote support?

- How do we inform individuals that there is personal responsibility to use such tools responsibly and that there is a requirement to take ownership of the presenting problem - in other words, unlike medication, systems like this still rely on taking ownership of one's challenges, change in one's thinking, habits, etc.

- Is there a way to track progress and pick up on 'warning' signs that could inform the user's therapist when the patient's mental health status becomes worse and trends toward for example self-harm in some form and how do we manage such instances?

- How do we ensure that therapists do not become too reliant on the use of the technology to solve the problem for them and for the patient?

- Are there any medical conditions we should consider when designing VR tools for mental health (e.g.: eye damage, eye health, injuries occurring)?

- Given the cost and availability, connectivity, and hardware/software requirements of VR technologies, might this in some instances generate a feeling of unfair treatment for those who cannot afford the technology or have access to the technology?

- What are the risks of having built-in monitoring systems for tracking early warning signs in terms of data privacy and patient rights?

- There is possibility of equipment damage, theft, malfunction, and need for insurance or replacement. In what ways should such concerns be managed when VR technology is 'prescribed' as part of a therapeutic intervention?

\section{REFERENCES}

[1] Addis DR, Hach S, Tippett LJ: Do strategic processes contribute to the specificity of future simulation in depression? Br J Clin Psychol 55:167-86, 2016

[2] Brezinka V: Computer games supporting cognitive behaviour therapy in children. Clin Child Psychol Psychiatry 19:100-10, 2014.

[3] Coyle D, McGlade N, Doherty G, O'Reilly G: Exploratory evaluations of a computer game supporting cognitive behavioural therapy for adolescents. Proc 2011 Annu Conf Hum factors Comput Syst - CHI '11 [Internet] New York, New York, USA: ACM Press; page 29372011 [cited 2018 Feb 13]. Available from: http://dl.acm.org/citation.cfm?doid=1978942.1979378
[4] Cummings CM, Caporino NE, Kendall PC: Comorbidity of anxiety and depression in children and adolescents: 20 years after. Psychol Bull 140:816-45, 14AD.

[5] Ehret AM, Joormann J, Berking M: Examining risk and resilience factors for depression: The role of self-criticism and selfcompassion. Cogn Emot [Internet] 29:1496-504, 2015. Available from:

http://www.embase.com/search/results?subaction=viewrecord\&from $=$ export\&id=L6008663

42\%5Cnhttp://dx.doi.org/10.1080/02699931.2014.992394\%5Cnhttp: //sfx.metabib.ch/sfx_loc ater?sid=EMBASE\&issn=14640600\&id=doi:10.1080\%2F02699931. 2014.992394\&atitle=Exami ning + risk

[6] Eichenberg C, Schott M: Serious Games for Psychotherapy: Games Health J 6:127-35, 2017.

[7] Falconer CJ, Rovira A, King JA, Gilbert P, Antley A, Fearon P, Ralph N, Slater M, Brewin CR: Embodying self-compassion within virtual reality and its effects on patients with depression. Br J Psychiatry Open [Internet] 2:74-80, 2016. Available from: http://bjpo.rcpsych.org/lookup/doi/10.1192/bjpo.bp.115.002147

[8] Fleming T, Dixon R, Frampton C, Merry S: A Pragmatic Randomized Controlled Trial of Computerized CBT (SPARX) for Symptoms of Depression among Adolescents Excluded from Mainstream Education. Behav Cogn Psychother [Internet] 40:52941, 2012 [cited 2018 Feb 13]. Available from: http://www.ncbi.nlm.nih.gov/pubmed/22137185

[9] Fleming TM, Bavin L, Stasiak K, Hermansson-Webb E, Merry SN, Cheek C, Lucassen M, Lau HM, Pollmuller B, Hetrick S: Serious games and gamification for mental health: Current status and promising directions. Front Psychiatry 7:, 2017.

[10] Freeman D, Reeve S, Robinson A, Ehlers A, Clark D, Spanlang B, Slater M: Virtual reality in the assessment, understanding, and treatment of mental health disorders. Psychol Med 47:2393-400, 2017.

[11] Gilbert P: The origins and nature of compassion focused therapy. $\mathrm{Br}$ J Clin Psychol 53:6-41, 2014.

[12] Gilbert P, Clarke M, Hempel S, Miles JNV, Irons C: Criticizing and reassuring oneself: An exploration of forms, styles and reasons in female students. Br J Clin Psychol 43:31-50, 2004.

[13] Hach S, Baghaei N, Jauny R, Hayward C, Sarrafzadeh A: MoodRush : Designing a Language- free Mobile App for Mood Selfassessment. Proc 7th EAI Int Conf Wirel Mob Commun Healthc Springer; 2017.

[14] Hach S, Tippett LJ, Addis DR: Neural changes associated with the generation of specific past and future events in depression. Neuropsychologia [Internet] Elsevier; 65:41-55, 2014. Available from: http://dx.doi.org/10.1016/j.neuropsychologia.2014.10.003

[15] Kirby JN: Compassion interventions: The programmes, the evidence, and implications for research and practice. Psychol Psychother Theory, Res Pract 90:432-55, 2017.

[16] Knox M, Lentini J, Cummings T, McGrady A, Whearty K, Sancrant L: Game-based biofeedback for paediatric anxiety and depression. Ment Health Fam Med [Internet] Radcliffe Publishing and Wonca; 8:195-203, 2011 [cited 2018 Feb 13]. Available from: http://www.ncbi.nlm.nih.gov/pubmed/22942901

[17] Leaviss J, Uttley L: Psychotherapeutic benefits of compassionfocused therapy: An early systematic review. Psychol Med 45:92745, 2015.

[18] Longe O, Maratos FA, Gilbert P, Evans G, Volker F, Rockliff H, Rippon G: Having a word with yourself: Neural correlates of selfcriticism and self-reassurance. Neuroimage [Internet] Elsevier Inc.; 49:1849-56, 2010. Available from: http://dx.doi.org/10.1016/j.neuroimage.2009.09.019

[19] Merry SN, Stasiak K, Shepherd M, Frampton C, Fleming T, Lucassen MFG: The effectiveness of SPARX, a computerised self help intervention for adolescents seeking help for depression: 
randomised controlled non-inferiority trial. BMJ [Internet] 344:e2598, 2012. Available from: http://www.ncbi.nlm.nih.gov/pubmed/22517917\%5Cnhttp://www.pu bmedcentral.nih.gov/a rticlerender.fcgi?artid=PMC3330131

[20] Ministry of Health: A Strategy to Prevent Suicide in New Zealand [Draft] [Internet]. Ministry of Health; 2017. Available from: http://www.health.govt.nz/system/files/documents/publications/strate gy-prevent-suicide-nz-draft-consultation_apr17.pdf

[21] Ministry of Health: Suicide Facts Deaths and intentional self-harm hospitalisations 2013. 2016.

[22] Morina N, Ijntema H, Meyerbröker K, Emmelkamp PMG: Can virtual reality exposure therapy gains be generalized to real-life? A meta-analysis of studies applying behavioral assessments. Behav Res Ther 74:18-24, 2015.

[23] Rawal A, Collishaw S, Thapar A, Rice F: A direct method of assessing underlying cognitive risk for adolescent depression. J Abnorm Child Psychol 41:1279-88, 2013.

[24] Shinohara K, Honyashiki M, Imai H, Hunot V, Davies P, Churchill $\mathrm{R}$ : Behavioural therapies versus other psychological therapies for depression. [Review] . Cochrane database Syst Rev 10:CD008696, 2013.

[25] Stallard P, Richardson T, Velleman S, Attwood M: Computerized CBT (Think, Feel, Do) for Depression and Anxiety in Children and Adolescents: Outcomes and Feedback from a Pilot Randomized Controlled Trial. Behav Cogn Psychother [Internet] 39:273-84, 2011 [cited 2018 Feb 13]. Available from: http://www.ncbi.nlm.nih.gov/pubmed/21272393

[26] Valmaggia LR, Latif L, Kempton MJ, Rus-Calafell M: Virtual reality in the psychological treatment for mental health problems: An systematic review of recent evidence. Psychiatry Res [Internet] Elsevier; 236:189-95, 2016. Available from: http://dx.doi.org/10.1016/j.psychres.2016.01.015

[27] Zeng N, Pope Z, Lee J, Gao Z: Virtual Reality Exercise for Anxiety and Depression: A Preliminary Review of Current Research in an Emerging Field. J Clin Med [Internet] 7:42, 2018. Available from: http://www.mdpi.com/2077-0383/7/3/42

[28] Moore C. Khaliq I., Fowles J. Theorizing gamified virtual reality approach to overcome fear of height. Lecture Notes of the Institute for Computer Sciences, Social Informatics and Telecommunications Engineering, 233:173 - 182, 2018.

[29] Giuseppe, R., Banos, R.M., Cristina, B., Fabrizia, M., Andrea, G. Transforming Experience: The Potential of Augmented Reality and Virtual Reality for Enhancing Personal and Clinical Change. Frontiers in Psychiatry 7:164, 2016. Available from: https://www.frontiersin.org/articles/10.3389/fpsyt.2016.00164/full

[30] Bouchard, S, Dumoulin, S, Robillard, G, Guitard, T, Klinger, E, Forget, H, Loranger, C, Roucaut, FX: Virtual reality compared with in vivo exposure in the treatment of social anxiety disorder: A threearm randomised controlled trial. British Journal of Psychiatry, 210(4):276 - 283, 2017.

[31] Petkova VI, Khoshnevis M, Ehrsson HH. The perspective matters! Multisensory integration in egocentric reference frames determines full-body ownership. Front Psychol 2: 35, 2011.

[32] Slater M, Spanlang B, Sanchez-Vives MV, Blanke O. First person experience of body transfer in virtual reality. PLoS One 2010; 5: e10564.

[33] Petkova VI, Ehrsson HH. If I were you: perceptual illusion of body swapping. PLoS One 2008; 3: e3832.

[34] Martini M, Perez-Marcos D, Sanchez-Vives MV. Modulation of pain threshold by virtual body ownership. Eur J Pain 18: 1040-8, 2014.

[35] Mental disorders, 9 April 2018 (accessed June 2018). http://www.who.int/en/news- room/factsheets/detail/mentaldisorders.

[36] Facts about young new Zealanders and depression, accessed June 2018. https://www.mentalhealth.org.nz/assets/A-Z/Downloads/FS2Facts-about-young-New- Zealanders-depression.pdf
[37] World Health Organization, Mental Health, accessed June 2018. http://www.who.int/mental_health/en/

[38] Early intervention in Mental Illness, accessed June 2018. https:/www2.health.vic.gov.au/mental-health/prevention-andpromotion/early-intervention-in-mental-health

[39] Kroenke K, Spitzer RL, Williams JBW. The PHQ-9 - validity of a brief depression severity measure. J Gen Intern Med 2001; 16: 60613.

[40] Falconer CJ, King JA, Brewin CR. Demonstrating mood repair with a situation based measure of self-compassion and self-criticism. Psychol Psychother 2015; 88: 351-65.

[41] Kannan D, Levitt HM. A review of client self-criticism in psychotherapy. J Psychother Integr 2013; 23: 166-78.

[42] Blatt SJ, Zuroff DC. Interpersonal relatedness and self-definition - 2 protypes for depression. Clin Psychol Rev 1992; 12: 527-62.

[43] Gaggioli A. Transformative experience design. In: Gaggioli A, Ferscha A, Riva G, Dunne S, Viaud-Delmon I, editors. Human Computer Confluence: Transforming Human Experience Through Symbiotic Technologies. Warsaw: De Gruyter Open (2015). p. 97121.

[44] Simpson, J., Duncanson, M., Oben, G., Adams, J., Wicken, A., Pierson, M., ... Gallagher, S. (2017). Te Ohonga Ake The Health Status of Māori Children and Young People in New Zealand Series Two (Health Status of Children and Young People). New Zealand Child and Youth Epidemiology Service. Retrieved from http://hdl.handle.net/10523/7390

[45] citation: Manea, L., Gilbody, S., \& McMillan, D. (2012). Optimal cut-off score for diagnosing depression with the Patient Health Questionnaire (PHQ-9): a meta-analysis. Cmaj, 184(3), E191-E196. https:/www.ncbi.nlm.nih.gov/pmc/articles/PMC3281183/ 